\title{
Mártires y cocineros: metáforas sobre el profesorado en columnas de opinión*
}

\author{
Paola Alarcón Hernández** \\ Claudio Díaz Larenas*** \\ Víctor Vásquez Bustos****
}

\section{Resumen}

El objetivo de la investigación es analizar las metáforas conceptuales sobre el profesorado presentes en dos columnas de opinión de ciberperiódicos chilenos. Ambas columnas fueron publicadas en el transcurso de la discusión de la ley Sistema de Desarrollo Profesional Docente. Se presentan las principales características de la metáfora conceptual y de los cibermedios. La investigación es de tipo cualitativo con alcance descriptivo exploratorio. Se aplicó el Procedimiento para la Identificación de la Metáfora y un análisis de contenido. Se analizaron las metáforas conceptuales el profesor es un mártir y el profesor es un cocinero. Mediante ambas metáforas se desarrolla una exposición sobre las condiciones laborales del profesorado y los factores del contexto de las que surgen.

Palabras clave: metáfora conceptual, columna de opinión, cibermedios, investigación cualitativa, profesores.

\section{Martyrs and Cooks: Metaphors on Teachers from Newspaper Columns}

\begin{abstract}
The aim of this research is to analyze the conceptual metaphors on teachers from two opinion columns in cyber newspapers. Both columns were published when the law about teachers' professional development was being discussed in parliament. The main characteristics of conceptual metaphor and cybernewspapers are outlined. The research is qualitative in nature and has got a descriptive and exploratory approach. The metaphor identification procedure and content analysis were used to process the data, and the metaphors the teacher is a martyr and the teacher is a cook were analyzed. Through both metaphors, teachers'
\end{abstract}

\footnotetext{
* Esta investigación fue financiada por el Fondo Nacional de Desarrollo Científico y Tecnológico (Chile) a través del proyecto FONDECYT Regular № 1171416 "Las representaciones sociales del profesorado chileno en ciberperiódicos. Un análisis del discurso en Lingüística Cognitiva”.

** Chilena. Doctora en Lingüística. Profesora Asociada del Departamento de Español, Facultad de Humanidades y Arte, Universidad de Concepción, Concepción, Chile. palarco@udec.cl

*** Chileno. Doctor en Educación. Profesor Titular del Departamento de Currículum e Instrucción, Facultad de Educación, Universidad de Concepción, Concepción, Chile. claudiodiaz@udec.cl

**** Chileno. Profesor de Español, Universidad de Concepción, Chile. Alumno del Magíster en Lingüística Aplicada de la Universidad de Concepción, Concepción, Chile. vicvasquez@udec.cl
} 
working conditions and the factors of the context in which these metaphors emerge are unfolded.

Keywords: Conceptual metaphor, Opinion column, Cybermedia, Qualitative research, Teachers.

\section{Introducción}

Durante la discusión sobre el proyecto de ley Sistema de Desarrollo Profesional Docente, diversas organizaciones de profesores llevaron a cabo una movilización nacional, en cuyo transcurso surgieron demandas relativas a las condiciones de desempeño del profesorado, en temas como el agobio laboral o la desvalorización de la profesión (Biscarra, Giaconi \& Assaél, 2015). En este contexto, el objetivo de la investigación que se presenta es analizar las metáforas conceptuales sobre el profesorado presentes en columnas de opinión de ciberperiódicos en el transcurso de la discusión de dicha ley.

El discurso del profesorado se debe comprender en el marco de las transformaciones a la educación pública instauradas por la dictadura cívicomilitar desde el año 1980, uno de cuyos resultados es el establecimiento de tres tipos de colegios: particulares, particulares con subvención estatal y municipalizados. Estos últimos eran los antiguos colegios públicos que dejaron de depender directamente del Estado y pasaron a hacerlo de los municipios. De acuerdo con Mizala y Romaguera (1998):

La reforma también permitió la incorporación del sector privado como oferente de servicios educacionales financiados con recursos públicos, al establecer un sistema de subvención por alumno, en un esquema de voucher. En un sistema clásico de subvención (voucher) el gobierno realiza un pago a las familias de forma que ellas puedan matricular a sus hijos en el colegio de su elección (público o privado). (p. 4-5).

Recientemente se promulgaron dos proyectos fundamentales para reformar el sistema educacional chileno vigente: Nueva Educación Pública y Sistema de Desarrollo Profesional Docente.

El Gobierno, encabezado por Michelle Bachelet, logró la promulgación de la ley Nueva Educación Pública en noviembre de 
2017. Esta ley tiene como objetivo fortalecer y mejorar la calidad de jardines, escuelas y liceos públicos. Además, pretende devolver al Estado el rol de garante del derecho a la educación, rol que se vio disminuido desde la dictadura cívico-militar, la cual "incentivó la provisión de servicios educacionales por parte del sector privado" (Mizala \& Romaguera, 1998, p. 4).

El otro proyecto, que es el que se aborda en este estudio, atañe a la carrera docente. Desde el inicio de la discusión en el Congreso, en 2013, la iniciativa propuesta por el Ejecutivo para establecer una carrera docente fue observada críticamente por el Colegio de Profesores y centros de investigación (Areyuna, 2013). Luego de diversas modificaciones seguidas por movilizaciones llevadas a cabo por organizaciones de profesores, el Sistema de Desarrollo Profesional Docente fue creado en abril de 2016 por la Ley 20.903. De acuerdo con la Agencia de calidad de la educación:

Su objetivo es reconocer la docencia, apoyar su ejercicio y aumentar su valoración para las nuevas generaciones, y para ello genera transformaciones relevantes para el ejercicio de la docencia. Aborda desde el ingreso a los estudios de pedagogía hasta el desarrollo de una carrera profesional que promueve el desarrollo entre pares y el trabajo colaborativo en redes de maestros. (Agencia de calidad de la educación, s/f).

No obstante, luego de la implementación de la ley, que comprende el aumento del tiempo no lectivo, una nueva escala de remuneraciones según niveles de desarrollo profesional y la formación continua, aún persisten las críticas, tanto al modelo evaluativo como a la pérdida de la centralidad del perfeccionamiento en cuanto parte del desarrollo profesional (Velásquez, 2017). La discusión sobre esta ley, que se plasma en los medios de comunicación, revela las formas en que las personas conciben el rol del profesorado y las condiciones profesionales en las que se desempeña.

Atendiendo a lo anterior, este estudio presenta un análisis de las metáforas conceptuales sobre el profesorado chileno identificadas en cibermedios. En primer lugar, se presentan una breve revisión de las características fundamentales de la metáfora conceptual y de los cibermedios. Posteriormente, se presenta la metodología adoptada por esta investigación para luego exponer los resultados del análisis y las conclusiones principales del estudio. 


\section{Marco conceptual}

\subsection{La metáfora conceptual}

El poder comunicativo de los conceptos metafóricos radica en su capacidad para englobar actitudes, valoraciones, emociones y puntos de vista sobre determinados conceptos. Así, cuando las personas se refieren a su trabajo como una carga difícil de llevar, están dando cuenta del esfuerzo, agotamiento y dificultades que demanda. Al mismo tiempo, se abren implicaciones como, por ejemplo, que no se está contento o satisfecho desarrollando ese trabajo y que posiblemente se desea abandonarlo.

Esta visión de la metáfora como un fenómeno fundamentalmente cognitivo fue impulsada por Lakoff y Johnson en el libro Metaphors we live by (1980), desde la Lingüística Cognitiva (Geeraerts \& Cuyckens, 2007; Ibarretxe-Antuñano \& Valenzuela, 2012). En lugar de considerar a la metáfora como un recurso lingüístico y literario más propio de poetas y retóricos, estos autores pusieron énfasis en la metáfora como un fenómeno del pensamiento, presente de manera inevitable en la vida cotidiana, y usado de manera inconsciente por todas las personas.

Lakoff y Johnson (1980) destacaron el carácter sistemático de los conceptos metafóricos. Retomando el ejemplo del inicio, en el conocimiento que surge de nuestras experiencias con las responsabilidades, donde una de ellas puede ser el trabajo o las tareas que se asumen, se identifica a la persona que tiene la responsabilidad, la responsabilidad misma y el esfuerzo involucrado. Por otro lado, hay un conocimiento de los componentes de la experiencia de llevar cargas o portar peso: la persona que carga peso, la carga, el gasto energético al llevar la carga, etc. El ámbito de la experiencia y de conocimiento, o dominio conceptual, que es metaforizado se denomina dominio meta, en este caso, las responsabilidades; el dominio conceptual que configura al dominio meta se denomina dominio fuente y, generalmente, es más accesible a la experiencia sensorial; en el ejemplo, portar cargas. La metáfora conceptual es el conjunto de correspondencias entre ambos dominios, por ejemplo: la persona que asume una responsabilidad corresponde a la persona que lleva la carga; desarrollar una tarea o responsabilidad corresponde a llevar una carga; el esfuerzo involucrado en tener la responsabilidad corresponde al gasto energético de llevar 
la carga; el deseo de dejar la responsabilidad corresponde al deseo de dejar de llevar la carga, etc. Como se puede apreciar, no se trata solo de referirse a las responsabilidades como cargas o pesos, sino que la lógica implicada en la experiencia de portar cargas permite razonar y comunicar ese razonamiento relativo a tener responsabilidades. La metáfora conceptual constituida por el conjunto de estas y otras correspondencias es las responsabilidades son cargas (por convención, en letra versalita).

Los primeros trabajos en metáfora conceptual se enfocaron precisamente en evidenciar la sistematicidad de los conceptos metafóricos junto con analizarlos desde diferentes perspectivas (Gibbs, 2008; Soriano, 2012). Actualmente, se observa un creciente interés por indagar en los factores contextuales que explican el surgimiento de metáforas en la interacción cotidiana (Kövecses, 2015) y en el análisis la metáfora conceptual en discursos especializados (Soares da Silva, 2016; Semino \& Demjen, 2017; Semino et al., 2018).

El estudio que se presenta sigue esta misma línea, pues se adopta una perspectiva sociocognitiva (Romano \& Porto, 2016) al tomar como supuesto que las representaciones sociocognitivas son estructuras compartidas, social y discursivamente construidas en el curso de la comunicación, que establecen identidades y relaciones sociales al ser comunicadas y que están sujetas a una transformación continua a través del flujo y reflujo de las relaciones intergrupales. Dada esta concepción, se analizan las conceptualizaciones metafóricas sobre el profesorado y su ejercicio profesional en el género de columna de opinión de ciperperiódicos.

\subsection{Cibermedios}

Actualmente se observa la creciente vitalidad de los medios digitales, los cuales constituyen una plataforma para el debate ciudadano sobre los más variados asuntos. En particular, en las diversas opiniones manifestadas en columnas de opinión, los ciudadanos expresan sus posiciones con respecto al rol de los docentes, a las condiciones de desempeño profesional y a las demandas que los movilizan.

Sin duda, las Tecnologías de la Información y las Comunicaciones han tenido un gran impacto en los medios de comunicación. La mayoría de los medios impresos mantiene hoy en día una versión en línea. Se observa también el surgimiento de medios que son exclusivamente electrónicos. 
Junto con la hipertextualidad y la multimedialidad, una de las características que han adquirido estas plataformas o cibermedios es la interactividad, la cual se define como "la posibilidad que ofrecen las plataformas online a los usuarios para que comenten, modifiquen o produzcan información a través de herramientas digitales puestas a su disposición por un medio, una red o una plataforma tecnológica" (García y Gutiérrez, 2011, p. 296).

La columna de opinión, género periodístico de carácter argumentativo, es un espacio en los periódicos donde el autor expone su punto de vista y las razones que lo sostienen sobre temas contingentes para el país o para ciertos sectores de la sociedad, como ha sido el caso de las columnas relativas a problemáticas del sistema educacional chileno.

Si bien Salaverría sostenía en 2005 que los géneros argumentativos eran los que menos habían aprovechado las posibilidades comunicativas ofrecidas por la red en cuanto a multimedialidad e hipertextualidad, reconocía que "sí se han abierto hasta cierto punto a la interactividad, solicitando comentarios de los lectores u ofreciendo el correo electrónico del columnista para ponerse en contacto con él" (p. 177). Esta afirmación muestra la evolución de las plataformas electrónicas de los medios de comunicación, pues actualmente han incrementado los recursos multimediales exponiendo contenidos a través de audios, imágenes y videos. De manera similar, es posible observar un aumento de la hipertextualidad en la disposición de contenido de manera no lineal a través de vínculos a otras páginas web de manera que el lector tenga la mayor cantidad de antecedentes sobre los temas expuestos. En cuanto a la interactividad, ya no solo se manifiesta en correos electrónicos, sino que se observa un interés de los medios por conocer la opinión de sus lectores a través de la apertura de la sección 'comentarios'. Más aún, muchas veces el mismo contenido es replicado en Facebook u otras redes sociales, con lo cual aumenta la cantidad de reacciones de los lectores. Según Arancibia y Montencino (2013):

En el comentario coinciden, contrapuestas, renovación y repetición, es decir, en él se encuentran actos discursivos nuevos que reanudan y/o transforman el acto discursivo original. Esta especie de repetición renovada que aparece tan claramente articulada en el comentario es una de las características fundamentales del género, lo que le permite deconstruir, recrear y crear indefinidamente visiones de mundo. (p. 126). 
Aunque pueda discutirse el real grado de participación que logren los ciudadanos -o ciberciudadanos- en su interacción con los medios electrónicos, es evidente que, lejos de las tradicionales 'cartas al director' en papel, en la actualidad los lectores pueden exponer sus comentarios apenas leen los contenidos en línea, marcando tendencias que, a veces, son tema de discusión en los propios medios.

\section{Metodología}

La investigación es de tipo cualitativo, pues "se fundamenta en una perspectiva interpretativa centrada en el entendimiento del significado de las acciones de seres vivos, sobre todo de los humanos y sus instituciones, busca interpretar lo que va captando activamente" (Hernández, Fernández \& Baptista, 2010, p. 9). De acuerdo con este paradigma, lo que llamamos 'realidad' se construye mediante las interpretaciones que los participantes del estudio realizan respecto de sus propias experiencias.

El alcance de la investigación es descriptivo exploratorio, dado que, aunque pretende describir un fenómeno, como corresponde a los estudios de tipo descriptivo (Hernández et al., 2010), no se encuentran referencias contundentes sobre trabajos que utilicen los mismos conceptos teóricos que la investigación; de ahí su carácter exploratorio.

\subsection{Corpus}

La selección del corpus de basó en un muestreo por criterio. De acuerdo con Mejía (200o), este tipo de muestreo consiste en seleccionar aquellas unidades que cumplen con criterios predefinidos. Para este estudio se establecieron como criterios: que el tema tratara sobre el profesorado y sus condiciones laborales; y que el lapso temporal estuviera comprendido en el periodo 2014-2017, periodo incluido en la discusión sobre el proyecto de ley Sistema de Desarrollo Profesional Docente, a partir de la cual surgieron opiniones sobre el profesorado chileno.

Se analizaron dos columnas en dos medios electrónicos:

- "La movilización de los profesores: la dignidad docente está en el centro", columna escrita Darío Vásquez, secretario general del Colegio de Profesores de Chile a la fecha. Fue publicada en El Mostrador, medio exclusivamente electrónico el 6 diciembre de 2014. 
- "Profesores: más dignidad es más calidad”. Sus autores son Gabriel Boric, Diputado por Izquierda Autónoma a la fecha (renunció a este movimiento en 2016 para integrar el Movimiento Autonomista), y Daniela López, integrante de Izquierda Autónoma. Esta columna fue publica en The Clinic Online, medio con versión impresa y en línea, el 4 junio de 2015.

\subsection{Procedimiento de identificación y análisis de la metáfora conceptual}

Se utilizó el Procedimiento para la Identificación de la Metáfora (MIP) propuesto por Pragglejaz Group (2007). En primer lugar, se leen las columnas completas para tener una comprensión general de su significado. Posteriormente se determinan los ítems léxicos. Para cada ítem léxico en el texto, se establece su significado en contexto, es decir, cómo se aplica a una entidad, relación o atributo en la situación evocada por el texto (significado contextual). Para cada ítem léxico, se determina también si tiene un significado contemporáneo más básico en otros contextos que el del contexto de la columna. Los significados básicos tienden a ser más concretos (lo que evocan es más fácil de imaginar, ver, oír, sentir, oler y saborear); relacionado con la acción corporal; más preciso (a diferencia de vago); históricamente más antiguo (se debe aclarar que los significados básicos no son necesariamente los significados más frecuentes de la unidad léxica). Si el ítem léxico tiene un significado contemporáneo más básico en otros contextos que en el contexto dado, se debe decidir si el significado contextual contrasta con el significado básico, pero puede ser comprendido en relación con él. En caso afirmativo, la unidad léxica se etiqueta como metafórica.

Una vez identificadas las metáforas lingüísticas se procede al análisis de contenido para la metáfora. Tomando en consideración las propuestas de Moser (2000), Saban, Kocbeker y Saban (2007), Saban (2010) y Alarcón et al. (2018), se siguieron las siguientes etapas para esta investigación: clarificación, eliminación, categorización y juicio de pares.

La etapa de clarificación de las metáforas corresponde a la identificación de los componentes de la metáfora conceptual en las metáforas lingüísticas: dominio meta, dominio fuente y correspondencias. Como se explicó previamente, el dominio meta es el concepto que pasa a ser metaforizado (en este caso, profesores, desempeño profesional docente, etc.). El dominio fuente es el concepto que configura al dominio 
meta. Las correspondencias son las relaciones que se establecen entre los elementos de ambos dominios. Luego se decide la eliminación de los casos dudosos, donde no es posible distinguir con precisión un dominio fuente. En la etapa de categorización se clasifican las metáforas conceptuales de acuerdo con el criterio semántico de la similitud; en particular, se agruparon por la coincidencia de dominio meta. Finalmente, en la etapa de juicio de pares, los resultados alcanzados individualmente son contrastados en sesiones de discusión del grupo de investigadores con el objetivo de llegar a consensos y definir el análisis de los casos dudosos.

\section{Análisis}

Las metáforas identificadas sobre los docentes y sus condiciones de desempeño profesional se entienden en el contexto de las críticas al estado actual de la educación pública, lo cual es muchas veces explicado también con metáforas, las que serán también descritas para otorgar el marco contextual al análisis.

\subsection{El profesor es un mártir}

Esa metáfora se desarrolla en la columna "La movilización de los profesores: la dignidad docente está en el centro". Darío Vásquez (2014), su autor, explica que el descontento del profesorado se debe a que, por una parte, las autoridades se han negado a resolver los problemas que afectan a la educación chilena desde hace más de treinta años y, por otra, a que no se hayan considerado en todo ese tiempo las opiniones docentes con relación a carrera profesional y al fortalecimiento de la educación pública.

En todo este periodo, según el autor, se ha instalado una predisposición para mirar con desconfianza y desprecio al docente. Esa desconfianza está en la base de las políticas hacia el profesorado y hacia la educación pública. Según Vásquez, se adjudica:

1. a la profesión docente el estado de postración en que está la educación pública.

Se indentifició aquí una personificación. De acuerdo con Lakoff y Johnson (2012), la personificación es un tipo de metáfora conceptual pues, mediante ella, dominios abstractos se conceptualizan mediante 
atributos humanos. Así, a través de la personificación la educación pública es una persona se conceptualiza a la educación como una persona en grave estado de salud de lo cual se culpa a los docentes, quienes son agentes patógenos. Según el autor, los docentes son muchas veces responsabilizados por la calidad de la formación de los estudiantes, lo cual, desde su perspectiva, es injustificado.

Para Vásquez, la visión que hay en la sociedad sobre el profesorado y las demandas de este se explican en un contexto de debilitamiento de la educación pública. Una de las causas de esta situación es el aumento del sector particular privado, que significó el:

2. retroceso en calidad [de la educación].

Mediante la metáfora progresar es avanzar, y una metáfora específica como es la calidad de la educación es un móvil, se declara que se debería incrementar la educación pública frente a la pérdida de calidad provocada por la irrupción de los establecimientos educacionales privados. El uso de esta metáfora implica que el avance es positivo y que, en lugar de eso, la educación en Chile va hacia atrás, lo que es evaluado negativamente. Para Vásquez, el Estado es el culpable del retroceso de la calidad de la educación y de la pérdida de un bien público, de ahí que el autor promueva la:

\section{3. recuperación de la educación pública.}

Tal como se observa en otras columnas (Alarcón, Díaz \& Vásquez, 2018), se usa la metáfora la educación pública es un bien, el cual ha sido arrebatado por el Estado en beneficio de los privados.

Esta exposición de la situación de la educación pública expuesto por el autor le permite explicar las condiciones de desemepeño profesional de los docentes, para lo cual recurre a la metáfora conceptual el profesor es un mártir:

4. El vía crucis que hoy padece la mayor parte de los profesores en sus trabajos /.../

De acuerdo con esta metáfora, las deficientes condiciones de desempeño del profesorado, ese vía crucis, se consideran como un castigo, que afecta su dignidad y desempeño profesional.

Las tareas y funciones que deben desarrollar los docentes se configuran en términos de cargas de acuerdo con la metáfora las responsabilidades son pesos. 
5. El agobio laboral docente, una verdadera sumisión a la que es obligado el profesor, ha hecho de la labor del profesor, un vía crucis diario que no le permite una vida familiar normal, y lo castiga con una carga laboral que debe continuar en su casa, quitándole horas al descanso y a su familia.

6. La profesión docente se ha transformado en una labor castigada por múltiples flancos. A una baja en la consideración social de su importancia, se suman la extensa y pesada jornada en medio de un agobio que no tiene parangón en otra profesión, /.../

Para explicar el descontento del profesorado el autor alude a temas como el respeto, la dignidad y valoración docente. El surgimiento de las demandas del profesorado es explicado mediante la metáfora:

7. El vía crucis que hoy padece la mayor parte de los profesores en sus trabajos, explica la explosión de rabia contenida que se ha hecho sentir /.../

Esta metáfora se basa en el esquema de imagen del contenedor: la rabia es un fluido caliente en un contenedor. Los esquemas de imagen constituyen un modelo y ordenamiento en nuestras acciones, percepciones y concepciones. Se definen como "un patrón recurrente, una forma y una regularidad en o de esas actividades de ordenamiento en curso" (Johnson, 1987/1991, p. 85). En algunos casos, estos esquemas constituyen los dominios fuentes de las metáforas y proveen elementos estructurales y una lógica específica. Por ejemplo, el esquema del contenedor se define por tener Interior, Límites y Exterior, y una lógica mediante la cual definir relaciones de inclusión o exclusión, como es el caso de las metáforas sobre la inmigración, que han sido estudiadas por Charteris-Black (2009). En el caso que se está analizando, se destaca que el interior tiene una capacidad limitada de contención. Metafóricamente, se establece que hay un límite para acumular la tensión que el profesorado ha ido albergando a lo largo de los años. Superado ese límite se produce un estallido de rabia, el cual provoca que los docentes manifiesten con fuerza sus demandas. Se señala además otro de los factores de este estallido:

8. La crisis que hoy detona en el sistema escolar está íntimamente asociada a la irrupción neoliberal en esta área.

Se apela nuevamente a la irrupción de los privados en la educación, ahora como factor que gatilla la manifestación de descontento del 
profesorado. Por otra parte, mediante la metáfora orientacional éxitofracaso es arriba-abajo, se expresa la crisis del sistema de educación pública:

9. La nuestra ha sido una crítica fundada. Nace de la experiencia de haber sido testigos de la caída de un sistema que no era perfecto $n i$ mucho menos, pero guardaba un espíritu democrático que se perdió, irremediablemente, cuando pasó a ser un negocio más.

En términos de Lakoff y Johnson (2012), la metáfora orientacional "organiza un sistema global de conceptos con relación a otro" (p. 50). Por ejemplo, el dominio total de la felicidad y la tristeza se configura en términos de un dominio espacial completo, como se observa en la metáfora felicidad-tristeza es arriba-abajo. De ahí surgen expresiones lingüisticas como 'andar subido o bajado', 'tirar para arriba', 'andar por los suelos', usadas metafóricamente para manifestar estados de ánimo. Generalmente, las metáforas orientacionales que tienen como dominio fuente el eje vertical configuran los estados negativos abajo y los positivos arriba, lo cual se oberva en el extracto (9), donde se conceptualiza la disminución de la calidad del sistema educacional como una caída, lo cual implica que abandonó un estado anterior más positivo, cuando el Estado tenía un rol mayor y no estaba marcado por la irrupción de los privados.

La metáfora conceptual las instituciones son edificios tiene una elaboración particular en el gremio de los profesores es un edificio:

10. /... / desde el primer día hemos apoyado sin ninguna aprensión ni duda la movilización de los profesores que se levantan desde la base y remueven los cimientos de nuestro gremio y de la sociedad chilena.

Esta metáfora se asocia en este extracto con la metáfora conceptual acción es movimiento que se expresa a través de la nominalización "movilización", una forma recurrente de referirse a las acciones ejercidas por las organizaciones sociales para exigir sus derechos. Mediante estas metáforas se hace un llamado a los docentes a que reaccionen ante sus condiciones profesionales y las de la educación pública, y a que realicen cambios fundamentales en las formas de posicionarse en cuanto movimiento gremial.

En síntesis, se identificaron metáforas referidas al profesorado, a la movilización y a la educación pública, las cuales permiten al autor desarrollar su exposición referente a las demandas de los docentes. 
Así, la metáfora los profesores son agentes patógenos muestra la visión que la sociedad injustamente tiene del profesorado según en autor, en un contexto de desmedro de la educación como se expone mediante las metáforas conceptuales la calidad de la educación es un móvil y éxito es arriba-frcaso es abajo. Esta concepción sobre la situación actual de la educación en Chile se comprende en un contexto donde se la conceptualiza como la educación pública es un bien, y se destaca el traspaso de esta a los intereses privados. Como consecuencia, se ha producido un empeoramiento de las condiciones laborales del profesorado, que tiene como efecto la concepción de las tareas y actividades profesionales como una onerosa carga que afecta el bienestar de los docentes, cuyo desempeño profesional se concibe como un martirio. La movilización del profesorado se comprende en este contexto y se explica a través de la lógica del esquema del contenedor, según la cual el contenedor tiene un límite para resistir la presión en su interior. El aumento de la rabia acumulada produce un estallido, producto del descontento. Finalmente, mediante las metáforas acción es movimiento y el gremio de los profesores es un edificio, el autor conmina al profesorado a actuar para producir cambios fundamentales que mejoren la calidad de la educación y las condiciones profesionales que incrementan el agobio laboral docente.

\subsection{El profesor es un cocinero}

En la columna "Profesores: más dignidad es más calidad”, Gabriel Boric y Daniela López desarrollan una crítica al proyecto de ley sobre carrera docente propuesto por el gobierno de Michelle Bachelet. La columna fue publicada la misma semana en que se había iniciado una paralización indefinida por parte de los docentes en rechazo a dicho proyecto. Los autores expresan sus observaciones al sistema propuesto de categorización o 'encasillamiento' con cuatro niveles de desempeño y de sueldos, que no considera la realidad de contratación del profesorado ni el contexto de desempeño, entre otras críticas al proyecto.

Boric y López plantean que las reformas educacionales postdictadura se han implantado de acuerdo con una lógica de mercado. Como consecuencia, el profesorado ha perdido su carácter profesional. Según los autores:

11. El despojo del carácter de funcionarios públicos a fines de los 80'y la delegación a corporaciones privadas (municipalidades) dibuja 
un camino de precarización laboral que no se detiene, continúa con la elaboración por parte de Gobierno y "expertos" en educación, de políticas públicas y discursos que sólo han socavado la dignidad profesional de los docentes.

Al igual que en la columna anterior, se considera como factor determinante de las condiciones del profesorado la privatización de la educación pública. En este párrafo se identificaron tres metáforas. Por una parte, la metáfora del despojo: la condición profesional es un bien; los profesores tenían un bien que les ha sido arrebatado por las políticas públicas. Luego, la precarización laboral es desplazamiento, basada en la metáfora conceptual los procesos son desplazamientos que permite configurar la precariedad laboral como un largo proceso, que aún se mantiene, llevado a cabo por el Estado. En este proceso, los docentes han ido perdiendo sus derechos laborales y su dignidad profesional. La metáfora conceptual la dignidad profesional es un edificio permite expresar a los autores que la dignidad profesional ha sido debilitada, socavada, por las políticas públicas.

Luego se abordan las obligaciones que se le imponen al profesorado. Boric y López señalan que otra de las debilidades del proyecto de ley es el establecimiento de evaluaciones a los docentes, las que suman a las que ya han debido rendir para graduarse, con lo cual se les asigna a ellos la responsabilidad sobre la formación recibida y no a la universidad en la que se titularon. Además, se les exige que sus alumnos obtengan buenos resultados en pruebas estandarizadas. Para ello, algunos colegios han implementado:

12. programas "recetarios" que tienen como único objetivo mejorar los resultados en las pruebas estandarizadas, transformando al profesor en un mero ejecutor de dichas recetas, la incorporación de una evaluación docente escasamente representativa de realidad laboral y la posterior clasificación a partir de esos resultados, son elementos que continúan y consolidan los pilares impuestos por la dictadura, profundizados por la Concertación y que hoy cobran aún más claridad con la reciente presentación por el Ejecutivo del proyecto de ley de Carrera Docente.

Se identifica aquí la metáfora conceptual el profesor es un cocinero, la cual se comprende en un contexto donde las autoridades educacionales imponen procedimientos para estandarizar el desempeño y mejorar los resultados de los alumnos. Los programas que debe seguir el docente corresponden a las recetas, la autoridad educacional que los crea y 
regula su ejecución corresponde al creador de la receta. En este marco, el ejercicio profesional se remite a ejecutar dichos procedimientos, así como un cocinero sigue las instrucciones de una receta para ejecutar un plato de comida. Como consecuencia, el docente pierde la posibilidad de innovar y, en teoría, cualquier persona provista de esas mismas recetas podría ejercer como profesor.

Según la columna, esta concepción del ejercicio profesional es una herencia de la dictadura cívico-militar que no ha sido modificada por los gobiernos democráticos posteriores. La metáfora mediante la cual se configura esta concepción es los sistemas educativos son edificios de acuerdo con la cual la dictadura construyó un sistema educativo. La privatización de la educación pública, la estandarización del currículum, la desconfianza expresada en la evaluaciones docentes y la pérdida de la dignidad profesional del profesorado son algunos de los pilares de ese edificio. Esos pilares han sido profundizados por los gobiernos democráticos, en lugar de haber sido eliminados y reemplazados por otros.

En síntesis y concordantemente con la columna anterior, se aborda aquí de manera crítica la pérdida del rol del Estado en la educación pública y se exponen las consecuencias para la dignidad y el ejercicio profesional docente. Como muestra la metáfora conceptual el profesor es un cocinero, las políticas públicas han tenido como resultado la desprofesionalización de la docencia, ya que cualquiera que esté provisto con esas mismas recetas puede desempeñarse como profesor. Esta concepción se observa en otros estudios que ha realizado este equipo de investigadores. Así, en la investigación de metáforas en estudiantes de pedagogía en etapa de práctica profesional, mediante un cuestionario de obtención de metáfora y un grupo focal (Alarcón et al., 2014) se evidenció que los sujetos usaron la metáfora del el profesor es un robot para referirse a las prácticas pedagógicas que se orientan a reproducir un currículo estandarizado, exigiendo a los docentes resultados óptimos. Según Alarcón et al. (2014, p. 89), “este tipo de práctica produce consecuencias asociadas al debilitamiento de la innovación pedagógica en el aula, además de la instrumentalización de la práctica docente". Según lo que se infiere del grupo focal, esta visión se explica a partir de la percepción de un contexto donde las condiciones de desempeño docente se caracterizan por una excesiva carga laboral a la que se suman procesos evaluativos y exigencias relativas a la utilización de material pedagógico. 
Como se observa, tanto el profesor cocinero y el profesor robot muestran las mismas condiciones de contexto.

\section{Conclusiones}

La discusión sobre la carrera docente es un tema que se mantiene aún hoy vigente, dado que recién se está implementado la ley Sistema de Desarrollo Profesional Docente. El análisis presentado da cuenta del uso de la metáfora conceptual en los columnistas para desarrollar sus posiciones con respecto al proyecto de ley, en las cuales sobresale la crítica a la privatización del sistema público y su traspaso a las municipalidades. Esa es la base para abordar las conceptualizaciones metafóricas sobre el profesorado. A pesar de tratarse de metáforas diferentes, se observa un trasfondo común en EL PROFESOR ES UN COCINERO Y EL PROFESOR ES UN MÁRTIR tanto en las implicaciones como en el contexto que las explica, tal como ya se expuso. Es importante destacar que estas metáforas no resultan extrañas al equipo investigador y seguramente tampoco a quienes son asiduos a los medios de comunicación chilenos. Estas muestran una crítica sostenida del profesorado sobre sus condiciones laborales, desvalorización social y la desprofesionalización que, en su percepción, han experimentado en las últimas décadas.

En este estudio se ha pretendido evidenciar la contribución de la metáfora conceptual al desarrollo de los argumentos de los columnistas. Dado el género analizado, no se puede tener certezas con respecto al nivel de uso inconsciente de las metáforas, ya que es posible suponer que hay aquí mayor nivel de conciencia en el uso del lenguaje metafórico a diferencia de la conversación cotidiana.

Como se mostró en este estudio, las metáforas conceptuales comprenden un complejo de visiones sobre la realidad, donde es posible identificar una dimensión evaluativa, la cual puede ser ampliada y formalizada en investigaciones posteriores mediante la Teoría de la Valoración (Martín \& White, 2005). Asimismo, el equipo de investigadores trabaja en la selección de un modelo para la caracterización de las columnas desde el punto de vista de la argumentación, para luego identificar el papel de la metáfora conceptual en la estructura de la argumentación. Al mismo tiempo, se está analizando el uso de la metáfora conceptual en los comentarios a las columnas de los cibermedios. Por ejemplo, ya se ha identificado el uso de la metáfora conceptual el profesor 
es una niñera en el mismo contexto de discusión sobre la ley Sistema de Desarrollo Profesional Docente. Esta metáfora se focaliza también en la desprofesionalización del rol docente al atribuirle principalmente la función de cuidar a los niños mientras los padres trabajan, coincidiendo con los resultados aportados por estudiantes de pedagogía en otros estudios (Alarcón et al., 2014). Se debe señalar que el estudio de los comentarios a las columnas muestra las particularidades de los cibermedios. Así por ejemplo, la columna de Darío Vásquez revisada en el presente estudio no tiene espacio para los comentarios en el medio que la publica, a diferencia de la columna de Boric y López que sí lo tiene. Como fase de la recopilación del corpus, este equipo revisa cada columna en Facebook, donde se observa una mayor interacción, tanto en los comentarios al columnista como entre los comentaristas.

Este equipo de investigadores espera que el estudio presentado constituya un aporte a los estudios del discurso desde un enfoque más bien reciente como es la metáfora conceptual y que los resultados de esta investigación se reactiven en la lectura de los medios de comunicación donde se expone la problemática del profesorado, tema siempre relevante y actual.

\section{Referencias bibliográficas}

Alarcón, P., Vergara, J., Concha, R. \& Díaz, C. (2014). ¿Robots, niñeras o héroes? Conceptualizaciones metafóricas del rol del docente". Paideia, 54, 75-98.

Alarcón, P., Díaz, C., Vergara, J., Vásquez, V. Torres, C. (2018). Análisis de metáforas conceptuales sobre la imagen social del profesorado en estudiantes de pedagogía. Onomázein, 40, 1-27.

Alarcón, P., Díaz, C., Vásquez, V. (2018). Un análisis de columnas de opinión desde la metáfora conceptual. Signo y Pensamiento. [enviado].

Agencia de calidad de la educación. (s/f). Nueva ley de carrera docente. Santiago: Gobierno de Chile. Recuperado de http://www. agenciaeducacion.cl/noticias/nueva-ley-carrera-docente/

Arancibia, M. C. \& Montecino, L. (2013). El blog de comentarios a textos de opinión en ciberperiódicos: un género en constante reconstrucción. Literatura y Lingüística, 28, 123-148. 
Areyuna, H. (12 de septiembre 2013). Profesores y especialistas cuestionan proyecto de ley de carrera docente. DiarioUChile. R ecuperado de http://radio.uchile.cl/2013/09/12/profesores-yespecialistas-cuestionan-proyecto-de-ley-de-carrera-docente/

Biscarra, C., Giaconi, C. \& Assaél, J. (2015). El docente en la legislación educacional chilena. Psicoperspectivas, 14(3), 80-92.

Boric, G. \& López, D. (4 junio de 2015). Profesores: más dignidad es más calidad. The Clinic On line. Recuperado de http://www.theclinic. cl/2015/06/04/profesores-mas-dignidad-es-mas-calidad/

Charteris-Black, J. (2009). Gran Bretaña como contenedor: metáforas sobre inmigración en la campaña electoral de 2005. Discurso \& Sociedad, 3(3), 467- 494.

García, V. \& Gutiérrez, L. (Eds.) (2011). Manual de géneros periodísticos. Bogotá: Ecoe Ediciones.

Geeraerts, D. \& Cuyckens H. (Eds.). (2007). The Oxford Handbook of Cognitive Linguistics. Oxford: University Press.

Gibbs, R. (2008). Metaphor and Thought. The State of the Art. En R. Gibbs (Ed.), The Cambridge Handbook of Metaphor and Thought (pp. 3-13). Cambridge: Cambridge University Press.

Hernández, R., Fernández, C. \& Baptista, P. (2010). Metodología de la investigación, 5ta ed. México, D.F.: McGraw Hill.

Ibarretxe-Antuñano, I. \& Valenzuela, J. (Eds.). (2012). Lingüística Cognitiva. Barcelona: Anthropos.

Johnson, M. ([1987]1991). El cuerpo en la mente. Madrid: Debate.

Kövecses, Z. (2015). Where metaphors come from. Oxford: Oxford University Press.

Lakoff, G. \& M. Johnson. ([1980] 2012). Metáforas de la vida cotidiana. Madrid: Cátedra.

Martín, J. \& White, P. (2005). The language of evaluation: Appraisal in English. Londres: Palgrave.

Mejía, J. (2000). El muestreo en investigación cualitativa. Investigaciones sociales, 4(5), 165-180.

Mizala, A. \& Romaguera, R (1998). Desempeño Escolar y Elección de Escuelas: La Experiencia Chilena. Serie Economía $N^{\circ} 36$. Santiago, Chile: Centro de Economía Aplicada, Departamento de Ingeniería Industrial, FCFM de la Universidad de Chile. 
Moser, K. (2000). Metaphor analysis in psychology: method, theory, and fields of application [22 paragraphs]. Forum: Qualitative Social Research, 1(2), Art. 21, Recuperado de http://www.qualitativeresearch.net/index.php/fqs/article/view/1090/2387

Pragglejaz Group. (2007). MIP: A method for identifying metaphorically used words in discourse. Metaphor and Symbol, 22(1), 1-39.

Romano, M \& Porto M.L. (Eds.). (2016). Exploring discourse strategies in social and cognitive interaction. Amsterdam: John Benjamin Publishing Company.

Saban, A. (2010). Prospective Teachers' Metaphorical Conceptualizations of Learner. Teaching and Teacher Education, 26, 290-305.

Saban, A., Kocbeker, B. N., \& Saban, A. (2007). Prospective teachers' conceptions of teaching and learning revealed through metaphor analysis. Learning and Instruction, 17, 123-139.

Salaverría, R. (2005). Cibermedios. El impacto de internet en los medios de comunicación en España. Sevilla: Comunicación Social Ediciones y Publicaciones.

Semino, E. y Demjen, Z. (Eds.). (2017). The Routledge Handbook of Metaphor and Language. Londres: Routledge.

Semino, E. y Demjen, Z., Hardie, A., Payne, S. A., \& Rayson, P. E. (2018). Metaphor, Cancer and the End of Life: A Corpus-based Study. Londres: Routledge.

Soares da Silva, A. (2016). The persuasive (and manipulative) power of metaphor in 'austerity' discourse. En M. Romano y M. L. Porto (Eds.), Exploring discourse strategies in social and cognitive interaction (pp. 79-108). Amsterdam: John Benjamin Publishing Company.

Soriano, C. (2012). La metáfora conceptual. En I. Ibarretxe-Antuñano y J. Valenzuela, (Eds.), Lingüística cognitiva (pp. 97-121). Barcelona: Anthropos.

Vásquez, D. (6 diciembre, 2014). La movilización de los profesores: la dignidad docente está en el centro. El Mostrador. Recuperado de http://www.elmostrador.cl/noticias/opinion/2014/12/06/ la-movilizacion-de-los-profesores-la-dignidad-docente-estaen-el-centro/

Velásquez, F. (14 de julio 2017). Carrera Docente: ¿se inicia con el pie izquierdo? las críticas del mundo docente al proceso. 
DiarioUChile. Recuperado de http://radio.uchile. cl/2017/07/14/carrera-docente-se-inicia-con-el-pieizquierdo-la-criticas-del-mundo-docente-al-proceso/ 